\title{
Análise de migração Kirchhoff e Stolts em dados terrestres da Bacia do Parnaíba.
}

Alípio Farias Martins - FAGEOF/UFPA.

Jeferson Afonso Santos - FAGEOF/UFPA.

Rodolfo André Neves - FAGEOF/UFPA.

Jaime Andrés Collazos Gonzáles - CPGF/UFPA.

Prof. Dr.João Carlos Ribeiro Cruz - CPGF/UFPA.

Copyright 2014, SBGf - Sociedade Brasileira de Geofísica

Este texto foi preparado para a apresentação no VI Simpósio Brasileiro de Geofísica, Porto Alegre, 14 a 16 de outubro de 2014. Seu conteúdo foi revisado pelo Comitê Técnico do VI SimBGf, mas não necessariamente representa a opinião da SBGf ou de seus associados. É proibida a reprodução total ou parcial deste material para propósitos comerciais sem prévia autorização da SBG.

\section{Abstract}

By using 1000 shots of the 2D seismic line 0295-0001, provided by the National Petroleum Agency (ANP) project called 0295_ANP_2D_PARNAIBA (TEIXEIRA, 2010), we reprocess them and make the comparison between the applications of Kirchhoff and Stolt migration methods.

The processed seismic line has $10 \mathrm{Km}$ length with a split-spread arrangement corresponding to 420 CDPs. The used seismic source was dynamite with 963 shots and 12 geophones per group, with spacing of $2.08 \mathrm{~m}$. The interval between groups of geophones was $25 \mathrm{~m}$, with a minimum spacing of $25 \mathrm{~m}$ and a maximum of $5237 \mathrm{~m}$. The total recording time was 5 seconds, but previously studies conducted in the area, indicated the maximum time of geological interest is $3.0 \mathrm{~s}$.

We used the PROMAX software for processing and applied the standard terrestrial data flowchart presented in this work, to obtain stacked and migrated time sections with the creation of a good velocity model.

\section{Introdução}

A Bacia Intra-cratônica do Parnaíba, localizada na região nordeste ocidental brasileira, possui espessura máxima de 3.500 metros, e abrange a área de aproximadamente $600.000 \mathrm{Km}^{2}$. Desenvolveu-se sobre um embasamento continental durante o estágio de estabilização da plataforma Sul-Americana (ALMEIDA e CARNEIRO, 2004). Sua forma é Elipsoidal, também dita "forma em prato", com diâmetro longitudinal medindo aproximadamente $1000 \mathrm{~km}$, e o diâmetro perpendicular a este com aproximadamente $800 \mathrm{~km}$.

Esta Sinéclise é bordejada ao sul pelo Arco de São Francisco, a leste e Oeste por rochas da orogenia Brasiliana. A borda noroeste da bacia é delimitada pelo arco de Tocantins, que separa esta bacia da Bacia do Amazonas. Ao norte existem duas bacias costeiras (Bacias de São Luiz e de Barreirinhas), que são separadas da Bacia do Parnaíba pelo Arco de Ferrer Urbano Santos.

Os processos deposicionais que afetaram essa bacia foram principalmente de natureza termal. A origem ou subsidência inicial da Bacia do Parnaíba provavelmente está ligada às deformações e eventos térmicos fini- e pós-orogênicos do Ciclo Brasiliano ou ao estágio de Transição da plataforma (ALMEIDA;CARNEIRO, 2004).

A Bacia do Parnaíba possui cinco Supersequências (Siluriana, Mesodevoniana-Eocarbonífera, Neocarbonífera-Eotriássica, Jurássica e Cretácea) cujas três primeiras estão situadas, no contexto da Plataforma Sul-Americana, no estágio de estabilização. Suas discordâncias são originadas devido às variações dos níveis eustáticos dos mares epicontinentais do Eopaleozóico (PETROBRAS, 2007). E as duas últimas estão associadas a eventos magmáticos de idades Jurotriássica a Eocretácia (GÓES; FEIJÓ, 1994) (Figura 1).

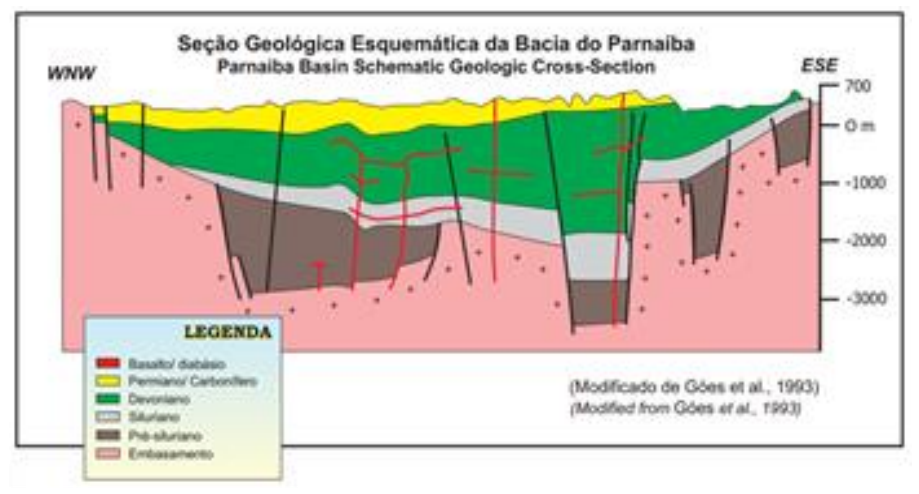

Figura 1 - Geologia do local (Modificação de Goés et al, 1993).

\section{Objetivos e Localização da Linha}

Este trabalho tem por finalidade discutir a aplicação das metodologias de migração Kirchhoff e Stolt, e de correções estáticas de elevação e refração, abordando a sua robustez, tempo de processamento e aplicabilidade no reprocessamento de dados sísmicos da Bacia do Parnaíba.

Os dados utilizados para o reprocessamento foram o conjunto dos 1000 tiros finais da Linha Sísmica 2D 0295-0001, pertencente ao projeto da Agência Nacional do Petróleo (ANP) denominado de 0295_ANP_2D_PARNAIBA (TEIXEIRA, 2010). A linha 0001 foi escolhida dentre o grupo das 9 do Projeto denominadas Linhas 0295-0001, 0295-0002, 02950004, 0295-0005, 0295- 0006, 0295-00030295-0007, 0295-0008 e 0295-0009 (Figura 2). A Linha 0295-0009 foi planejada para passar sobre o poço 1-FL-1-PI. 


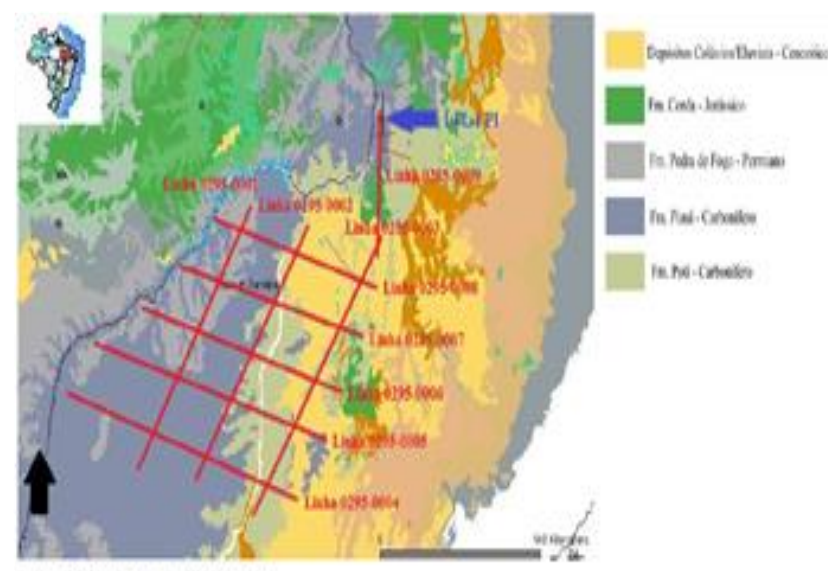

Fonte Modifisdo de ANP (2013)

Figura 2 - Linhas de levantamentos de dados sísmicos (ANP, 2013.).

O Software de processamento PROMAX foi utilizado, seguindo o fluxo de processamento apresentado no ítem Metodologia deste trabalho, com o intuito de obterem-se seções empilhadas (zero offset) e migradas no tempo, a partir das metodologias de Migração Kirchhoff e Stolt. O principal aspecto pretendido é o melhoramento da continuidade dos refletores, nas seções, a partir das correções estáticas de Elevação e de Refração, que possibilitam um melhor modelo de velocidades.

A linha de dados sísmicos que foi trabalhada tem dimensão de $10 \mathrm{Km}$, em arranjo split-spread,com 420 CDPs.O tipo de fonte usada foi dinamite, com 963 tiros. Foram usados 12 geofones por grupo, com o espaçamento de $2.08 \mathrm{~m}$. O intervalo entre grupos de geofones foi de $25 \mathrm{~m}$, com o mínimo afastamento de 25 $\mathrm{m}$ e o máximo de $5237 \mathrm{~m}$. O tempo total de registro foi de 5 segundos, porém observou-se em trabalhos realizados anteriormente na área, que o tempo máximo de interesse geológico é de $3 \mathrm{~s}$.

\section{Metodologia}

\section{Pré-Processamento}

Os 1000 tiros selecionados da Linha sísmica 0001, fornecidos em formato SEG-Y pela ANP, foram convertidos para o formato Seispace, para ralização do carregamento da geometria, informando-se as coordenadas das fontes e dos grupos de geofones (Receptores) (Figura 3).

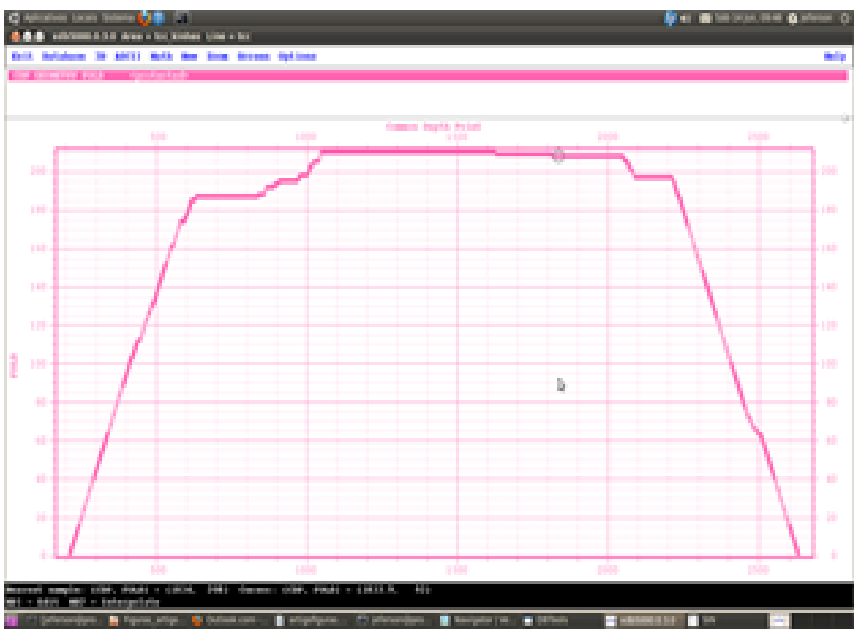

Figura 3 - Gráfico CDP x FOLD (cobertura) para os tiros selecionados. O máximo de cobertura é 210.

O pré-processamento dos dados já com a geometria carregada foi realizado pelas seguintes etapas: 1) Eliminação dos traços mortos (de amplitude zero) e eliminação das primeiras chegadas (refração): Usando o módulo "Top Mute" faz-se a demarcação de horizontes (picking) que é extrapolado até o tempo de início do levantamento. Toda essa área demarcada tem sua amplitude eliminada (multiplicada por zero). O módulo "Kill Trace" elimina traços muito ruidosos e de amplitude zero selecionados pelo usuário. 2) Correções de divergência esférica e atenuação: Através do módulo "True Amplitude Recovery", faz-se correções para a divergência esférica e atenuação inserindo-se uma função de velocidades $\mathrm{V}(\mathrm{t})$, semelhante a utilizada no "Brute Stack", ou uma tabela de velocidades. A Figura 5 demonstra o dado sem a utilização do TAR, assim como a Figura 6 demonstra o mesmo dado após a aplicação do TAR. 3) Aplicação da deconvolução, "spike decon": A Deconvolução (Decon Predictive), baseada na compressão da "wavelet" sísmica, melhora a resolução vertical no dado sísmico. Foi utilizada a deconvolução de fase mínima, sendo o comprimento do operador de deconvolução 320 e a distância do operador de predição 25. 4) Filtragem banda passante: $\mathrm{O}$ principal módulo de filtragem utilizada foi o filtro de banda passante Orsmby, de fase mínima, onde 0 usuário pode especificar as frequências utilizadas no processo de filtragem. As frequências utilizadas neste foram 6-12-60-90 Hz; com o intuito de atenuar o "ground roll" com frequencias abaixo de $6 \mathrm{~Hz}$ e ruídos de alta frequências acima de $90 \mathrm{~Hz} .5$ ) Acréscimo de ganho (AGC): O AGC (automatic Gain Control) é utilizado para ressaltar a amplitude dos eventos do dado (Figura 4). 


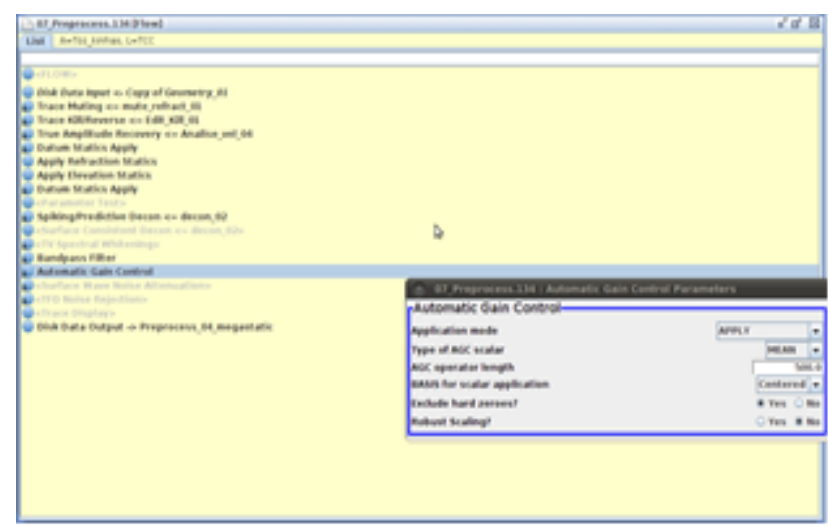

Figura 4 - Parâmetros do AGC aplicado (Automatic Gain Control).

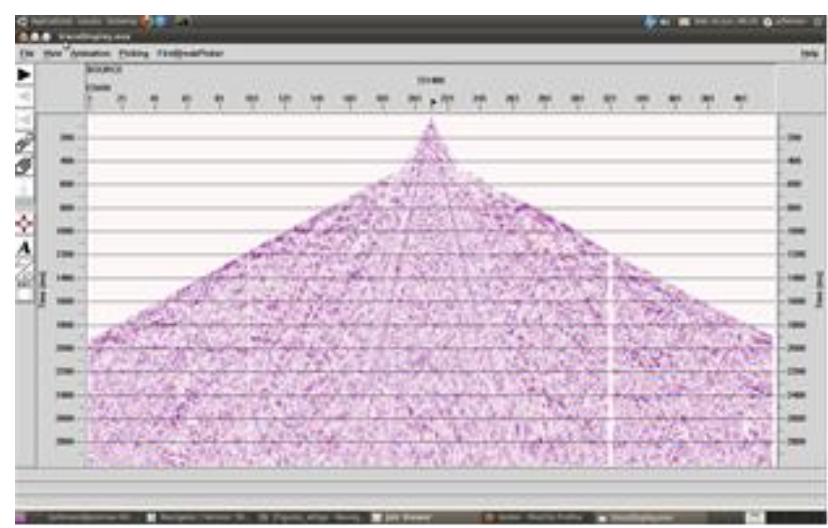

Figura 5 - Dado sem a utilização do TAR (True Amplitude Recovery).

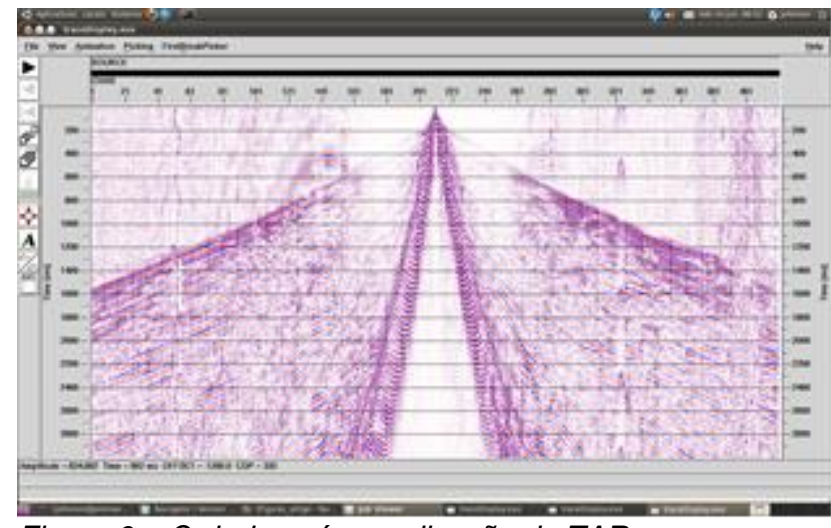

Figura 6 - O dado após a aplicação do TAR.

\section{Processamento}

O processamento da linha 2D 0295-0001foi realizado através da aplicação das seguintes etapas:

\section{1) Brute Stack:}

O Brute Stack, ou empilhamento preliminar, segue o mesmo algorítimo utilizado no empilhamento convencional: Os eventos de reflexão, em famílias CMP, são corrigidos de NMO e depois superpostos. Porém este se dá sem a utilização de um modelo de velocidades prévio (ou seja, não precisa de Análise de Velocidades para ser construído).
No Brute Stack, o usuário insere uma função de Velocidades $\mathrm{V}(\mathrm{t})$, onde $\mathrm{t}$ representa o Tempo que 0 programa irá utilizar como base para o empilhamento.

Ele fornece uma primeira visão do dado processado. Se os refletores têm mergulho, ou se são mais tabulares. É uma ferramenta interessante, pois fornece uma prévia do comportamento dos refletores.

\section{2) Correções Estáticas}

Para a aplicação da correção estática, é necessário o conhecimento de vários parâmetros, tais como: elevação do terreno, profundidade de carga utilizada no levantamento sísmico e velocidade e espessura da camada de intemperismo. Deve-se considerar que a mesma pode melhorar o resultado da seção sísmica processada, caso haja uma moderada variação lateral de velocidade da camada de baixa velocidade. No entanto, quando essa variação lateral aumenta de forma significativa, a aplicação não eficaz do processo pode causar distorções das estruturas mapeadas em subsuperfície (AMORIM, 1985).

As Correções Estáticas utilizadas foram de Elevação e de Refração:

A Correção estática de Elevação (Figura 7) corrige a partir da informação da topografia, os desvios no tempo de transito ocasionados pela diferença de elevação entre os receptores. Ou seja, fisicamente, transforma a seção original, com receptores em diferentes posições em $z$, para uma seção como se os receptores e fontes estivessem no mesmo nível topográfico (Datum).

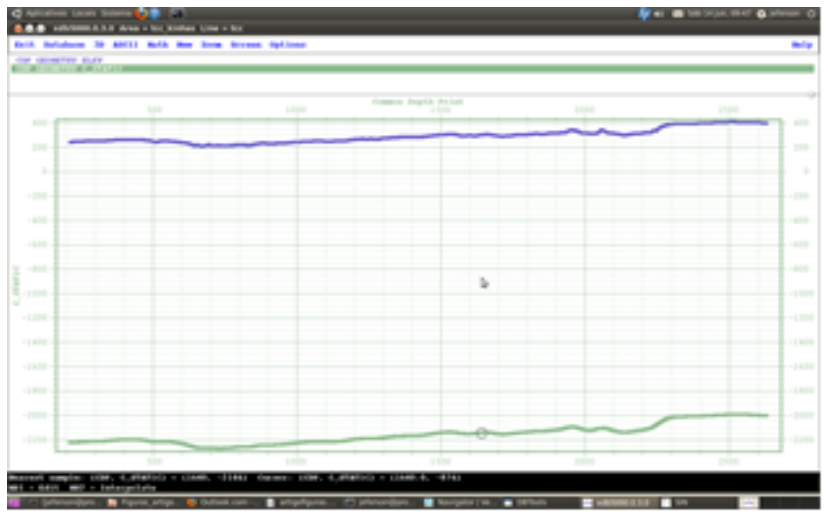

Figura 7 - Correção estática de Elevação.

A Correção Estática de Refração (figura 8) corrige as diferenças nos tempos de transito ocasionadas pelas camadas sedimentares rasas, denominadas camada ou zona de baixa velocidade (ZBV). O parâmetro de entrada necessário é o FB Pick (marcação das primeiras chegadas) e o tempo de uphole (que pode ser inserido a partir da tabela de Geometria, ou pode ser calculado pelo programa). 


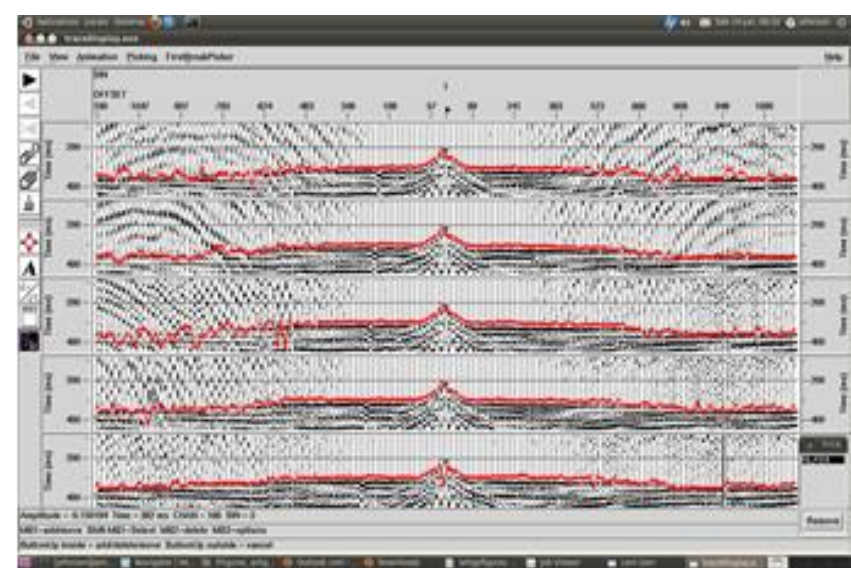

Figura 8- Correção Estática de Refração.

\section{3) Análise de Velocidades}

A análise de velocidades (Figura 9) utiliza como entrada um dado pré processado. A partir desse dado, é formado um supergather (conjunto de CDP's máximo e mínimo - Common Deep Point) para realizar um pré dado computacional de velocidade (velocity Precompute). Os "supergathers" são utilizados para a construção da análise de velocidade preliminar (o cdp Increment informa o incremento, o cdps to combine informa o número de cdps utilizados como conjunto em cada supergather.).

A tabela de velocidades é preparada como entrada na análise de velocidades, calculando-se o semblance (medida de coerência), e criando funções de velocidade de empilhamento (VFS) para um cdp predefinido.

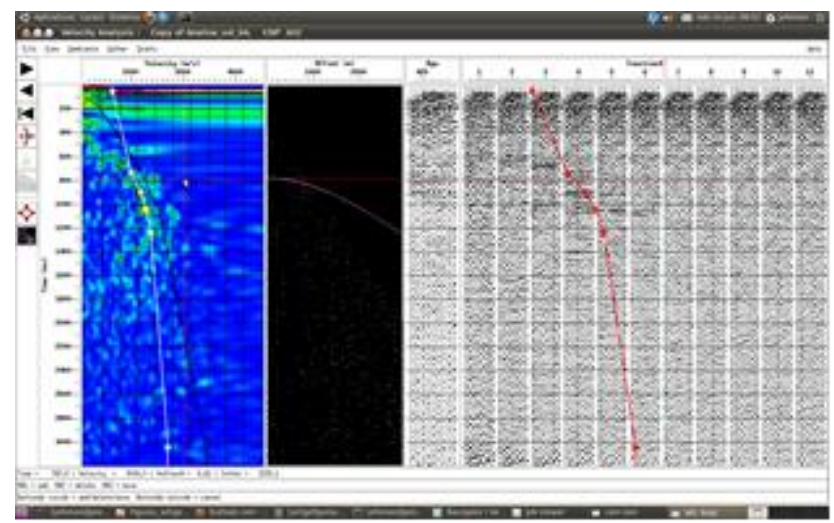

Figura 9 - análise de velocidades.

\section{4) Empilhamento}

O fluxo de empilhamento realiza a correção NMO e empilha os traços em CMP, utilizando como parâmetro um modelo de Velocidades construído na Análise de Velocidades.

$\mathrm{Na}$ etapa do empilhamento é realizada a soma aritmética das amplitudes dos traços das famílias CMP, após a correçãoo NMO. O resultado é uma aproximação da secão de afastamento nulo onde as reflexões são supostas abaixo da posição do CMP. A melhoria da razão sinal-ruído dos dados, nesse caso, dependerá do grau de coerência alcançada nos eventos de interesse (reflexões).

Esta situação em princípio é atingida em interfaces horizontais e modelos sem variação lateral de velocidade. Vale lembrar que, para uma interface com fortes mergulhos, as reflexões não provêm de pontos de reflexão exatamente abaixo do CMP.

O empilhamento CMP também pode minimizar a anuência de chegadas contaminantes, tais como ondas diretas ou ondas superficiais. Em consequência, esses eventos não são somados coerentemente no processo de empilhamento.

\section{5) Migração: Métodos Kirchhoff e Stolt}

A migração é um operador de inversão que envolve o rearranjo dos elementos de informação sísmica, então as reflexões e difrações são plotadas nos seus locais verdadeiros. Neste trabalho foram aplicados e comparados os métodos de migração Kirchhoff e Stolt, ambos no domínio do tempo, apresentados a seguir:

Migração Kirchhoff: A migração Kirchoff utiliza mapas de tempo de trânsito, que estão relacionados a cada superfície (refletores) em sub-superfície. Esse método utiliza a velocidade RMS, Vrms ( $x$, t) (root mean square; raíz da média dos quadrados), e atua no domínio tempo. Provém uma boa seção migrada para refletores com mergulho superior a $90^{\circ}$.

Migração Stolt: É muito boa para ambientes de velocidades horizontais constantes. Mas particularmente ineficiente para ambientes com grande variação de velocidades principalmente lateral. O algorítimo utiliza um método análogo ao "Stolt Streching", técnica para o cálculo da variação vertical e espacial de velocidade.

\section{Resultados}

A partir do Pré-processamento, uma saída foi gerada em disco. Esse dado pré-processado foi submetido ao "Brute Stack" (empilhamento preliminar). A figura abaixo representa o resultado do "Brute Stack" (Figura 10).

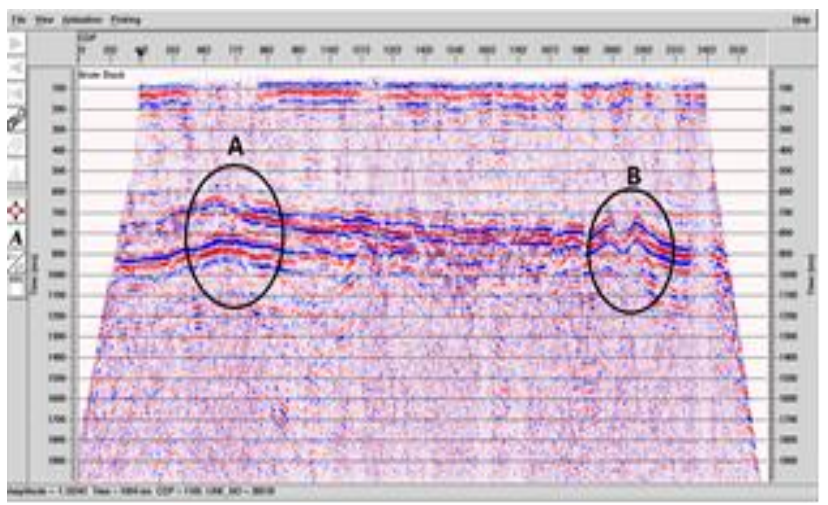

Fígura 10 - Resultado do "Brute Stack" (empilhamento bruto).

A seção Brute Stack apresenta refletores ligeiramente planos e com pequeno mergulho para a direita. Percebe-se também duas áreas com regiões dobradas identificadas como A e B. Esse conjunto de refletores 
aparecem na porção intermediária da seção entre 600$750 \mathrm{~s}$.

Com o intuito de melhorar a continuidade, e retirar os efeitos da topografia e da Zona de Baixa Velocidade (ZBV) foram realizadas as Correções Estáticas de Elevação e de Refração (Figura 11).

Percebe-se como a continuidade dos refletores melhora; estes estão mais planos, e as regiões anteriormente dobradas $A$ e $B$, tornaram-se mais contínuas. Isso pode ser observado na figura abaixo:

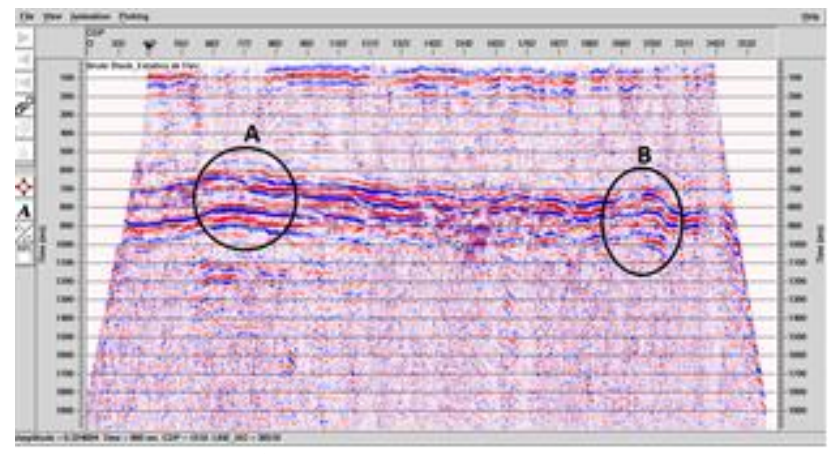

Figura11 - Brute Stack com estáticas.

A partir de então, realizou-se a Análise de Velocidades; para que a seção empilhada fosse melhorada. A Análise de Velocidades serve para encontrar o melhor modelo de Velocidades $\mathrm{V}(\mathrm{x}, \mathrm{t})$ possível que produza a soma coerente dos eventos de reflexão.

Como observado no "Brute Stack", a velocidade não deve variar muito lateralmente, então o modelo de velocidades mais coerente, deve variar verticalmente de maneira suave e apresentar continuidade horizontal.

Dentre os Modelos de Velocidades obtidos, o melhor Modelo de Velocidades produzido apresenta-se na Figura 12.

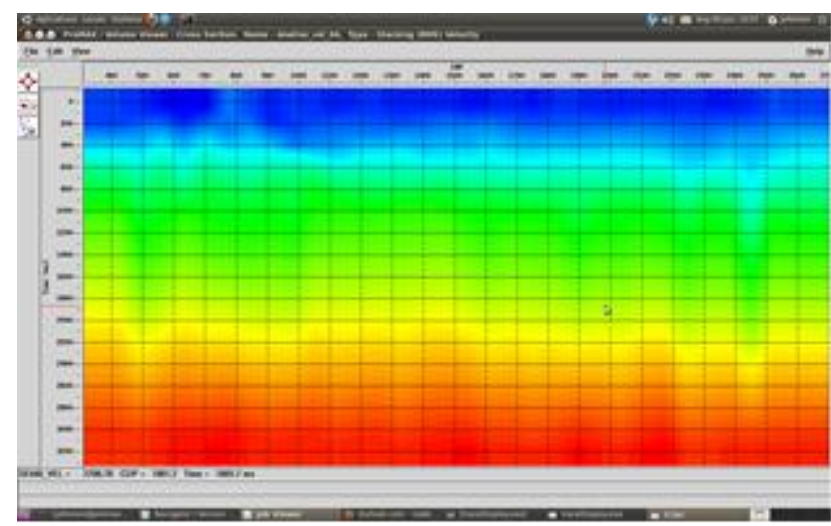

Figura 12 - Modelo de Velocidades produzido.

O critério de escolha do Modelo de Velocidades acima, foi o fato de que este produz a seção empilhada mais coerente (refletores contínuos) e semelhante a seção Brute Stack eventos de reflexão plano-tabulares. Abaixo na figura 13 segue a Seção Stack (Empilhada ou Zero-offset) produzida:

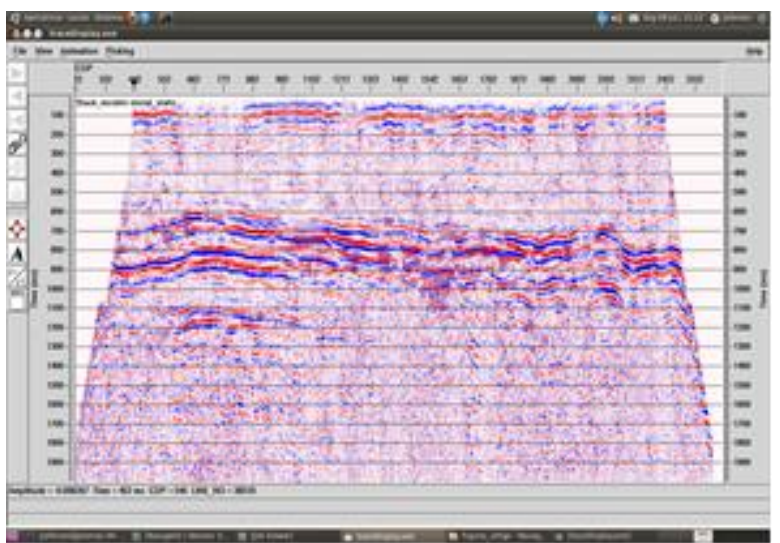

Figura 13 - Seção Stack (empilhada).

A etapa seguinte foi produzir-se as seções migradas. Com o objetivo de colapsarem-se as difrações e melhorar ainda mais a continuidade dos refletores. O primeiro método de Migração foi o Kirchoff, que produz a seção Migrada a partir da integral de Kirchoff. A seção resultante é apresentada na figura 14.

\section{Seção Migrada Kirchoff}

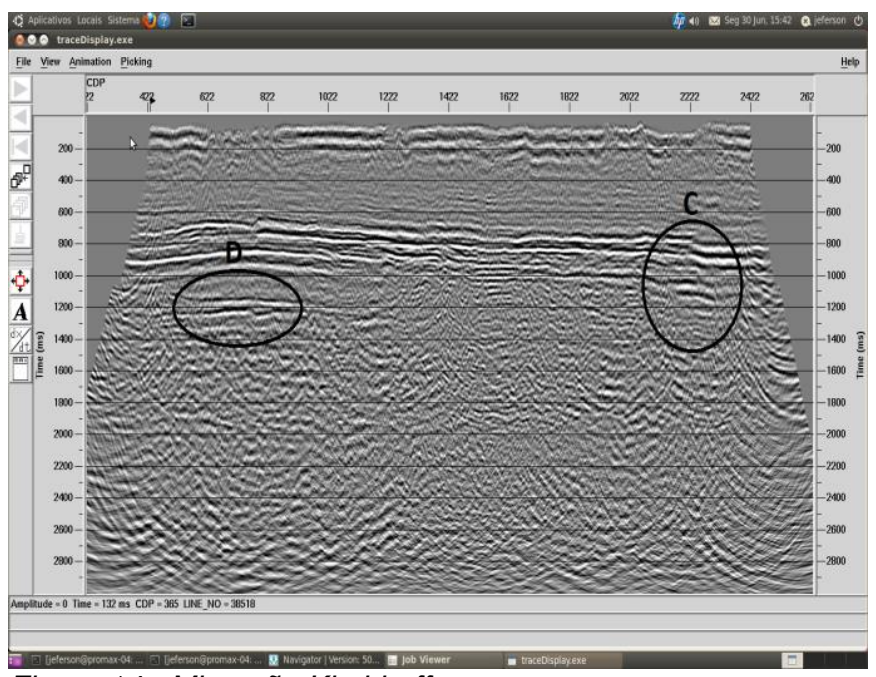

Figura 14 - Migração Kirchhoff.

Percebe-se que o processo de Migração Kirchoff não produz uma seção tão diferente da empilhada. A região " $C$ " destacada parece algum tipo de dobramento. 


\section{Seção Migrada Stolt.}

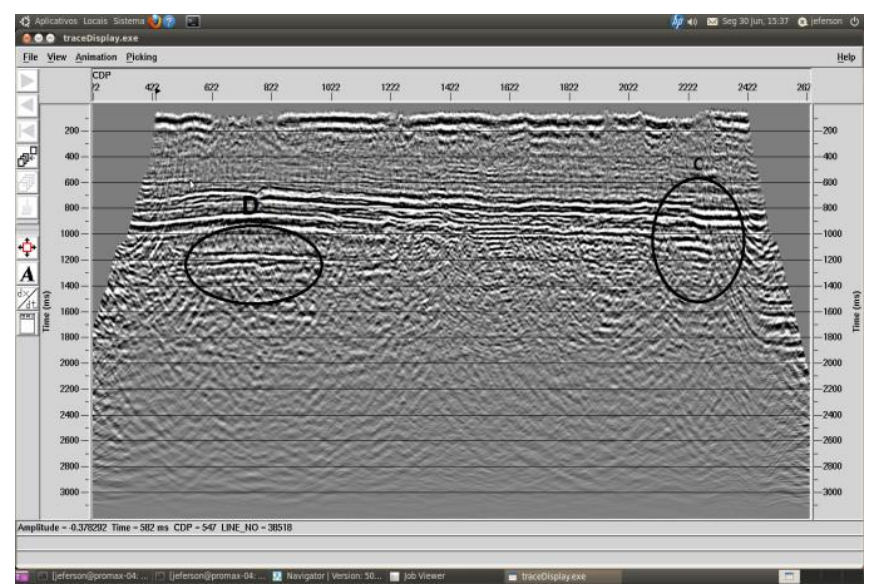

Figura 15 - A Migração Stolt.

$\mathrm{Na}$ região "C" o que parece ser um dobramento na migração Kirchoff, aparece como uma fratura na migração Stolt (fígura 15).

\section{Conclusões e Recomendações}

As correções estáticas de Elevação e de Refração representam ferramentas indispensáveis para 0 processamento de dados sísmicos terrestres. Pois a Falta dessas correções pode conduzir a erros de Interpretação, a exemplo das seções Brute Stack aqui apresentadas. Verificou-se que as dobras e descontinuidades nas regiões identificadas como $A$ e $B$, na realidade, eram devidas aos desvios no tempo de trânsito, provocados pelos efeitos da ZBV e Topografia, anteriores as correções estáticas.

Foi também ressaltado, que para o ambiente em questão, a Migração Stolt produziu resultado mais satisfatório em relação a acomodação geológica das camadas, se comparada a Migração Kirchoff. Isso se deu, pois a Migração Stolt se enquadrou melhor ao ambiente com deposições plano-tabulares e pouca ou nenhuma variação lateral de Velocidade.

Além disso, a Migração Stolt é melhor no quesito tempo de processamento. Essa Migração durou em média 3 minutos, enquanto que a Migração Kirchhoff durou entre 5 a 10 minutos. Visto que o dado processado possui apenas 1000 tiros da Linha Original [Quantos no total?] a diferença no tempo de cômputo seria muito maior se a Linha toda fosse processada, e maior ainda, se as nove Linhas do levantamento fossem utilizadas.

No entanto, em termos de relação sinal/ruído, Kirchhoff gera um modelo mais suave (vide figura 14), o que pode ser observado para esta comprovação é o destaque do ruído (círculo D) em ambas migrações, o contraste é mais intenso em Stolt, praticamente "poluindo" a imagem. Visto que o dado processado possui apenas 1000 tiros da Linha Original [Quantos no total?] a diferença no tempo de cômputo seria muito maior se a Linha toda fosse processada, e maior ainda, se as nove Linhas do levantamento fossem utilizadas.
Então, por fim, ambas migrações mostram-se importantes de serem observadas, cada uma com suas limitações, comprovando que o bom processamento atua na quantitatividade de métodos a serem utilizados. Vale ressaltar o peso das informações referentes à geologia do local analisado, tais como deposição, ângulos das camadas, etc. Pois são dados a serem considerados durante a aplicação das ferramentas de processamento.

\section{Agradecimentos}

ANP, Universidade Federal do Pará, Faculdade de geofísica, Centro de Pós-Graduação em geofísica, Instituto de Geociências e SBGF.

\section{Referências}

\section{AGENCIA NACIONAL DO PETROLEO (ANP). Bancos de dados. Disponível em: <http://www.bdep.gov.br/>}

Almeida, F. F. M. de, 1969. Diferenciação tectônica da Plataforma Brasileira (Tectonic differentiation of the Brazilian Platform). Proceedings 33rd. Brazilian Geological Congress, Salvador (BA), Brazil, vol. 1: 29-46.

B. Geoci. Petrobras, Rio de Janeiro, v. 15, n. 2, p. 253-263, maio/nov. 2007.

GÓES, A. M. O.; SOUZA, J. M. P.; TEIXEIRA, L. B. Estágio explorativo perspectivas petrolíferas da bacia do Parnaíba. Boletim de Geociências da PETROBRAS, Rio de Janeiro, v.4, n. 1, p. 55-64. 1990. GÓES, A. M. O.; FElJÓ J. F. Bacia do Parnaíba. Boletim de Geociências da Petrobras, Rio de Janeiro, v. 8, n. 1, p.57-67. 1994.

GÓES, A.M.O.; FElJÓ, F. 1994. Bacia do Parnaíba. Bol. Geoc. Petrobrás. Rio de Janeiro.

PROMAX Reference Manual Contents.

TEIXEIRA, F. S. Análise estrutural e estratigráfica de feições geológicas através da interpretação de seções sísmicas e de mapas gravimétricos, na porção Leste da Bacia do Parnaíba, PI. 2010. 92 f. Trabalho de Conclusão de Curso (Graduação em Geologia) - Universidade Federal do Rio de Janeiro, Rio de Janeiro, 2010. 